before the end of $T$, but more usually it starts at the end of $T$ or 0.01 or 0.02 sec. afterwards.

The sound curves from cases of mitral stenosis were taken in two series-a series over the area at which the diastolic murmur was audible, and a control series over areas at which the murmur was inaudible.

The positions and duration of the murmurs were estimated after careful comparison of the two sets of curves.

1. The time relation of the first and second sounds in the control curves of mitral stenosis are practically the same as in normal hearts. The sounds are usually much more intense, though of similar duration to those of the normal heart.

2 . When the heart is beating regularly and the sequence of contraction is normal, the shortest diastolic murmurs of mitral stenosis precede the first sound, and consequently precede the initial rise of intraventricular pressure. They lio in presystole.

3. Generally speaking the presystolic or diastolic murmur is not a crescendo; the crescendo is an effect of the proximity of the loud first sound. The vibration frequency of the murmur is from 41 to 107 per minute. The murmur begins from 0.05 to $0.22 \mathrm{sec}$. before the commencement of $R$ and runs up to the first sound. Usually it occupies the whole or greater part of diastole.

4. When fibrillation of the auricles is present an isolated presystolic murmur does not occur; the fixed tims relation of the murmur is to the early phases of diastole; the mur nur runs over a variable proportion of diastole, according to the variation in the length of the latter; in the longest diastoles and in slow acting hearts there is a period of silence between murmur and first sound; in a shortest diastole the murmur may occupy its whole extent.

5. When heart-block is present the position of the diastolic murmur is largely controlled by the position of the auricular contraction.

It is concluded that the diastolic murmurs of mitral stcrosis are due to the rapid onflow of blood through the stenosed mitral orifice. Those periods of diastole are occupied by murmurs, during which the velocity of flow reaches a certain grade. When the auricle contracts at the normal time and the heart beats slowly, the velocity tends to be greatest in presystole. Otherwise it is usually greatest in early diastole; these are the periods at which nurmurs arc most commonly audible.

\section{REGIONAL ANAESTHESIA.}

FELIX ROOD, M.B., B.S.DurH., M.R.C.S., L.R.C.P.LOND.

ASSISTANT ANAESTUETIST, VNIVERSITY COLLTGE TOSPITAL : IATE ANAESTHETIST, LONDON THROAT HOSPITAL.

THE greater attention recently devoted to the subject of anaesthesia, and greater knowledge of the subject, has rerealed dangers that were before unknown and has shown how very much the ultimate well-being of the patient depends upon a careful selection of the method of anaesthesia used. It is quite obvious that the remote dangers of somo annesthetic drugs are far greater than the immediate, and it does not seem improbable that these sequelae may be more scrious and far-reaching than we eren now realize.

As the dangers of general anaesthesia in ccrtain cases lare been more fully appreciated, more attention has been devoted to the subject of local anaesthesia ; so much so that if the condition of a patient is such that the adminis tration of a general anaesthetic is likely to be specially dangerous, almost any operation of necessity can be successfully and painlessly performed under some form of local anaesthesia.

Until comparativcly recent years local anaesthesia was very little used, on account of the toxicity of cocaine, the agent usually employed. But with the introduction of the comparatively innocuous substances, stovaine, novocain, and eucaine, considerable attention has been devoted to the subject, and great strides have been made in the technique of this form of anaesthesia.

Broadly speaking, local anaesthesia may be placed under three heads :

1. Spinal anaesthesia, in which some form of anaesthetic drug is introduced into the spinal theca.
2. Local infiltration anacsthesia, in this case a very weak solution of the anaesthetic drag is employed, and the whole area to be operated upon is infiltrated with the solution.

3. Regional anaesthesia, a stronger solution of the anaes. thetic drug is employed, and a small quantity is introduced around the nerve trunks which supply the part to be operated upon at some part of their course which is anatomically accessible.

The choice of the one or the other of these methods depends upon the condition of the patient, the necessities, and also upon the site of the operation. It is fortunate that for those cases in which one form is not suitable another frequently is. The advantages of spinal anaesthesia in septic abdominal conditions, especially acute appendicitis in the young, associated with much toxaemia, and in those cases in which abdominal relaxation is required, such as the radical cure of large irreducible herniae, ventral herniae, cases of intussusception and prostatectomy, are too well known to require further discussion herc.

For those cases, such as cysts in the upper part of tho breast, subcutaneons lipomata, the radical cure of hydrocele, varicocele, and varicose veins, in which it is often difficult, if not impossible, to isolate the nerve trunks supplying the part, the wide infiltration method with a weak solution is certainly preferable.

Regional anaesthesia can be used for any type of operation upon any part of the body supplied by nerves which are at some part of their course anatomically accessible By anatomically accessiblo is meant that the nerve shall lie in such a position that it is possible to pass a fino needle down to it, and so introduce the analgesic fluid. It is almost impossible to inject the fluid around a nerro lying amongst muscles, as the difficulty of gauging the depth from the surface is so great. Further, even if the needle is introduced into the neighbourhood of the nerve trunk, the point may casily liare passed through a laye. of fascia or the sheath of a muscle, so that howercr much fluid is introduced, it will not be distributed around the nerre. In some few instances this direction of the fluid by the fascia may bc utilized to facilitate the injection, the nerve itself lying in some fascial compartment, which can be filled up with anaesthetic solution. The musculospiral ncrve in the arm or the median at the wrist are both cases in point.

The characteristics of this form of anaesthesia are

1. Granted that a suitable anaesthetic solution is introduced around the trunk of a nerve, the whole area supplied by that nerre becomes anaesthetic--bone, muscle, fascia, skin, etc.

2. The method can be used for operations upon inflamed tissues provided that the injection around the nerve trunl be made at some point well above the septic area.

3. The anatomical relations of the part to be operated upon are not obscured by oedema caused by a large quantity of injected fluid, as is sometimes the case with the wide infiltration method.

4. The anaesthesia lasts for several hours.

5. The anaestlictic area is clearly defined by the anatomical distribution of the nerves. Consequently thero is no risk of suddenly overstepping the limits of the anaes. thesia, with most unpleasant results to the patient.

A very important factor in the success or otherwisc of this form of anaesthesia is the solution used.

Either cucaine, stovaine, or novocain may be employed, but the best results in my hands have been obtained with

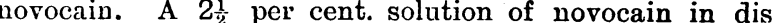
tilled water is prepared and sufficient sodium chloride added to make the fluid isotonic with the blood. The whole is then sterilized by boiling. which can be done without detriment to the norocain; it is, of course, absolutely necessary that this fluid should be sterile, and for this reason it should be freshly prepared for each case shortly before using. The formula of the solution is:

\section{Novocain}

$\begin{array}{lllll}\ldots & \ldots & \ldots & \ldots & 2.0 \\ \cdots & \ldots & \ldots & \ldots & 0.5 \text { gram }\end{array}$

5 drops of $a 1$ in $10,0 x 0$ solution of adrenalin are added to each $20 \mathrm{c.cm}$. of solution immediately before use.

When the fluid is injected into the tissues the vessels are 
constricted, and the solution consequently tends to be confined to the site of injection, so causing the anaesthesia to be more prolonged.

The apparatus required for the injection of the analgesic anaesthetic fluid consists of a syringe and a number of hollow needles; by far the most convenient form is the ordinary record syringe with glass barrel. This can be obtained in a variety of sizes; the most useful for this work is that graduated to $20 \mathrm{c.cm}$. A number of needles of different sizes and lengths, all detachable from the syringe barrel, are required.

The Technique of Injection.

It is absolutely necessary that this should be performed with the most rigid aseptic precautions. Under no circum. stances should the injection be made through an inflamed area or very near an infected area. The skin over the point at which the injection is to be made should be prepared as for a surgical operation. A solution of iodine in ethylene dichloride used as a paint immediately. before the injection is both convenient and effectual for this purpose. Some of the anaesthetic solution having been sucked up into the syringe, a very fine needle is introduced beneath the epidermis and a few drops of the solution injected, so that

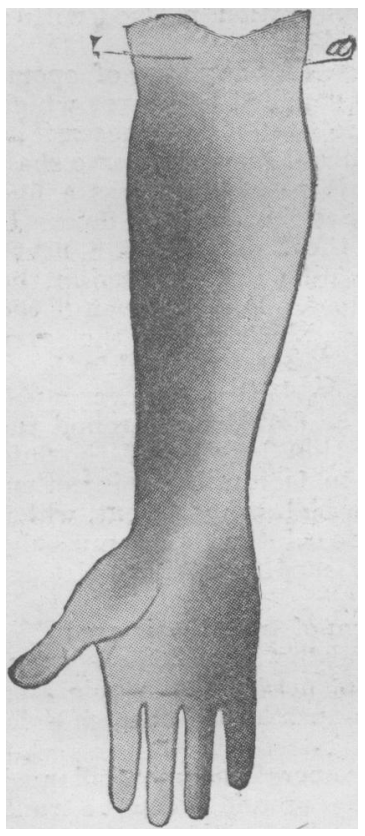

Fig. 1.

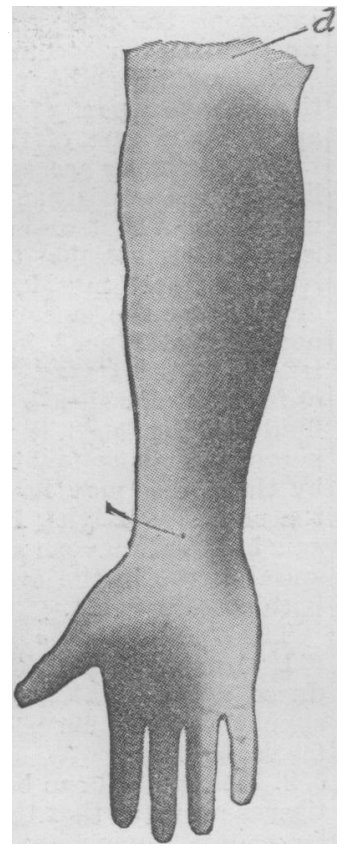

Fig. 2.
Anterior aspect of hand and forearm.

a minute blob is raised. This can be done with practically no pain. A slightly larger needle is next introduced through the blob down to the nerve trunk. When introducing the needle it is preferable to remove it from the barrel of the syringe, as it is much easier to gauge the exact position of the point if the heary syringe is not in place. As soon as one is satistied that the point of the needle is in the neighbourhood of the nerve trunk, the barrel of the syringe can be slipped into the wide base of the needle and the injection made.

The actual site of injection of course depends upon the nerve supply of the part to be operated upon. For instance:

To anaesthetize the index finger it is necessary to block the median and radial nerves; if it is desired to render the great toe anaesthetic, as for an operation for ballux valgus, it would be necessary to block the anterior tibial, musculo-cutaneous, internal saphenous, and internal plantar nerves.

It is frequently much easier to inject around a nerve trunk at a more proximal part of its course rather than around the actual branch which it is desired to anaes. thetize. Consequently it is preferable to inject around the musculo-spiral nerve in the arm than around the radial in the forearm. Again, one would never think of injecting the anterior tibial or musculo-cutaneous nerves in the leg, but would most certainly inject the external popliteal trunk.

As a general principle, it is easier to injcct around a nerve as it lies against a bone, as this provides a landmark which ensures that the right level is reached. It is very much more difficult to gauge the depth of a nerve than its position as regards surface marking. If possible, points should be chosen for injection where the nerve either lies against bone or on the deep fascia, not amongst muscles, etc.

The accompanying diagrams, prepared from actual cases, show some of the more convenient and useful points for blocking the nerve trunks and the anaesthesia following.

This method of anaesthesia demonstrates very clearly the remarkable overlapping of nerves in their distribution. Consequently it is often necessary to inject around moro nerves than at first sight seems anatomically requisite.

In the illustrations the degree of analgesia is indicated by the depths of shadow; the darkest portions represent complete loss of sensation.

$$
\text { Anterior Aspect of Hand and Forearm. }
$$

Fig. 1 illustrates anaesthesia following blocking of the

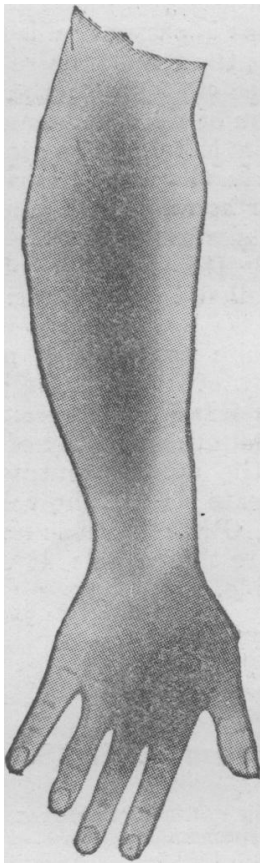

Fig. J.

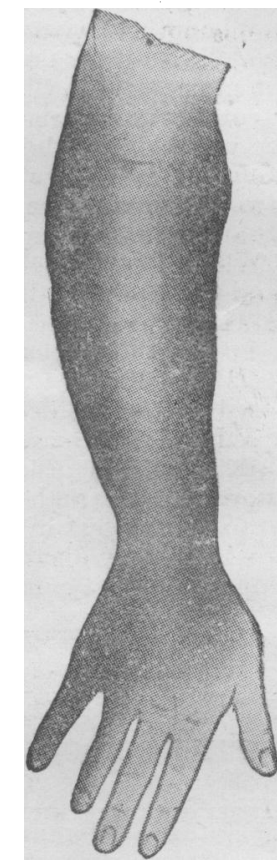

Fig. 4.
Back of hand and forearm.

ulnar nerve behind the internal condyle $(a)$ and musculo. cutaneous nerve at the outer side of the biceps tendon $(b)$. The introduction of the fluid around the ulnar nerve presents little difficulty. The nerve is easily felt lying behind the internal condyle. The nerve should be defined with the fingers, the forearm being extended. Then, keeping the finger on the nerve, flexing the forearm, the needle is introduced just external to the bony point of the condyle and passed outwards, keeping the point close to the bone. The needle will now lie between the bone and the nerve; 2 or $3 \mathrm{c.cm}$. of the fluid are injected, the needle is then withdrawn a little, the point passed superficial to the nerve, and 2 to 3 c.cm. more introduced. After withdrawing the needle the fluid is to be gently massaged into the nerve with the fingers.

To inject around the musculo-cutaneous nerve, pick up the skin and superficial fascia between the thumb and first finger just external to the tendon of the biceps, thus gauging the thickness of the superficial fatty layer, pass the needle down to the deep fascia, and make the injection upon the surface of this layer.

Anterior Aspect of Arm and Forearm.

Fig. 2 illustrates anaesthesia produced by blocking the internal cutaneous nerve at the elbow and the median at the wrist. 
To introduce the fluid around the internal cutaneous ncrve the injection should be made about $\frac{3}{4}$ in. internal to the tendon of the biceps upon the surface of the deep fascia. As the internal cutaneous nerve is at this point in two portions, the injection must be planned to cover a correspondingly wide area.

The median nerve at the wrist is easily found; it lies directly behind the tendon of the palmaris longus muscle. If this muscle is absent, the injection should be made $\frac{1}{2}$ in. internal to the tendon of the flexor carpi radialis muscle.

Back of Forear'm and Hand.

Fig. 3 illustrates the anaesthesia produced by blocking the misculo-spiral nerve in the groove on the outer side of the humerus.

In order to find the musculn-spiral nerve, take a point midway between the angle of the acromion and the olecranon process. This is the point at which the nerve crosses behind the humerus, and in nearly every case it can be palpated just below this level as it winds downwards and forwards.

The position of the nerve being thus defined, the needle is passed down to it till the point touches the outer side of the humerus. A liberal injection is made, which passes upwards and downwards in the fascial compartment which contains the nerve in this part of its course.

Fig. 4 illustrates anaestlesia produced by blocking the musculo-cutaneous, internal cutaneous, and ulnar ncrves.

\section{Anterior Aspect of Trunk.}

Fig. 5 illustrates anaesthesia produced by injection of intercostal nerres. On the left side the second, fifth, and eighth are shown. On the right side the nerves have been blocked, from the third to the tenth inclusive.

In each case the injection has been made just in front of the angle of the rib, consequently each intercostal nerve has been blocked well behind the origin of its lateral cutaneous branch.

The intercustal norves, lying as they do behind the

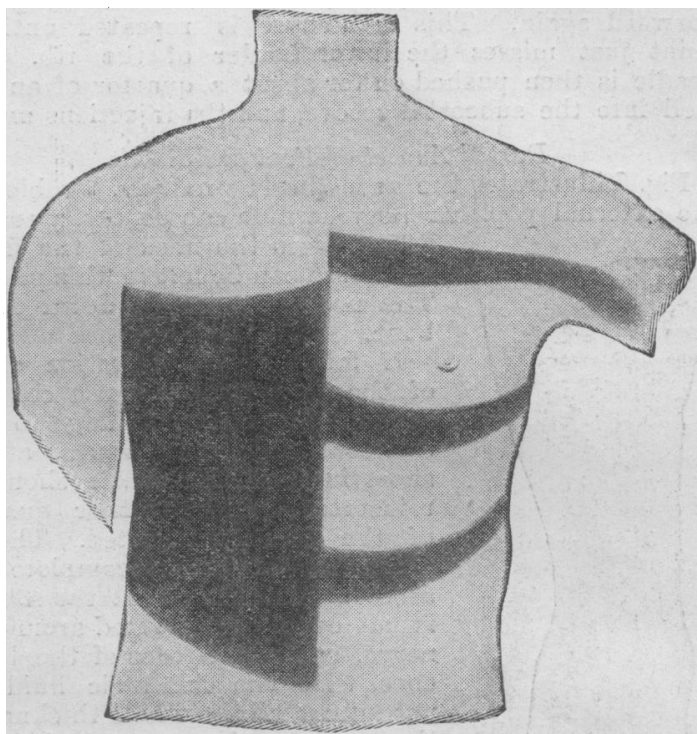

Fig. 5.

corresponcling ribs in the subcostal groove, can be raached with ease and certainty, the ribs forming an excellent bony landmark to their position. The patient should lie on his back with the arm raised. The rib covering

\begin{tabular}{|c|c|c|c|c|c|c|c|c|}
\hline Site of & Ope & ration. & & $\mid \begin{array}{c}\text { No. of } \\
\text { Cases. }\end{array}$ & Nature of Cases. & Operations. & Romarks. & Nerves Injected. \\
\hline HAND & ... & $\cdots$ & $\cdots$ & 150 & $\begin{array}{l}3 \text { Injury } \\
45 \text { Cellulitis } \\
102 \text { Whitlows }\end{array}$ & $\begin{array}{l}\text { Ipcision } \\
\text { Amputation of digits } \\
\text { Removal of necro: cd bone }\end{array}$ & Anaesthesia complete & $\begin{array}{l}\text { Median. } \\
\text { Musculo-spiral. } \\
\text { Ulnar. }\end{array}$ \\
\hline WRIST ANI & $D$ Fo & & & 17 & $\begin{array}{l}4 \text { Cellulitis } \\
9 \text { Ganglia } \\
1 \text { Amptitation } \\
2 \text { Removal. of sub- } \\
\text { cutaneous tumour } \\
1 \text { Excision of head of } \\
\text { radius }\end{array}$ & $\begin{array}{l}\text { Incision } \\
\text { Removal by dissection } \\
\text { Removal by dissection }\end{array}$ & $\begin{array}{l}\text { Anaesthesia complete } \\
3 \text { Cases completed under } \\
\text { gencral anaesthesia } \\
\text { Anaesthesia complete } \\
\text { Anaesthesia complete } \\
\text { Some sensation in the bone }\end{array}$ & $\begin{array}{l}\text { Median. } \\
\text { Ulnar. } \\
\text { Musculo-spiral. } \\
\text { Musculo-cutaneous. } \\
\text { Internal cutaneous. }\end{array}$ \\
\hline ARMr... & $\ldots$ & ... & ... & 1 & Old osteomyelitis & Removal of sequestrum & $\begin{array}{l}\text { Complete anaesthesia of } \\
\text { whole of arm }\end{array}$ & $\begin{array}{l}\text { Brachial plexus descend- } \\
\text { ing clavicular. }\end{array}$ \\
\hline Tirotax & ... & $\cdots$ & ... & 43 & $\begin{array}{l}12 \text { Adenomata of breast } \\
2 \text { Abscess of breast } \\
3 \text { Pericarditis } \\
6 \text { Empjemata } \\
2 \text { Abscess of lung } \\
14 \text { Intrathoracic con- } \\
\text { ditions } \\
1 \text { Tuberculous rib } \\
1 \text { Tuberculous ster- } \\
\text { num } \\
2 \text { Bronchiectasis }\end{array}$ & $\begin{array}{l}\text { Removal by dissection } \\
\text { Incision drainage } \\
\text { Removal of rib cartilage, } \\
\text { drainage } \\
\text { Removal of ribs, drainage } \\
\text { Incision, drainage } \\
\text { Puncture, incision, removal } \\
\text { of rib } \\
\text { Remoral of rib } \\
\text { Removal of diseased bone and } \\
\text { sequestra from a sterior and } \\
\text { posterior surfaces of sternum } \\
\text { Removal of ribs }\end{array}$ & 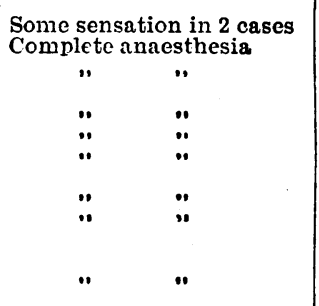 & Intercostais. \\
\hline ABDOMI: & ... & ... & ... & 6 & $\begin{array}{l}3 \text { Oesophageal ob- } \\
\text { struction } \\
1 \text { Acute cholecystitis } \\
1 \text { Cholelithiasis } \\
2 \text { Intestinal obstruc- } \\
\text { tion }\end{array}$ & $\begin{array}{l}\text { Gastrostomy } \\
\text { Removal of stones, drainage } \\
\text { Removal of gall stones from } \\
\text { gall bladder and common } \\
\text { duct } \\
\text { Colotomy: Paul's tube in- } \\
\text { serted into ileum }\end{array}$ & $\begin{array}{l}\text { Complete anaesthesia, no } \\
\text { pain when stomach was } \\
\text { drawn out } \\
\text { Complete anaesthesia } \\
\text { Peritoneum sensitive } \\
\text { Complete auacsthosia }\end{array}$ & $\begin{array}{l}\text { Intercostals. } \\
\text { Intercostals. } \\
\text { Intercostals. } \\
\text { Eighth and trelfth dor- } \\
\text { sal, ileo-hypog a trio, } \\
\text { ileo-inguinal. }\end{array}$ \\
\hline Fоот... & $\cdots$ & $\cdots$ & $\cdots$ & 37 & $\begin{array}{l}1 \text { Sarcoma } \\
3 \text { Cellulitis } \\
8 \text { Hallux va!gus } \\
6 \text { Injury } \\
9 \text { Hammer toe } \\
10 \text { Other conditions }\end{array}$ & $\begin{array}{l}\text { Syme's amputation } \\
\text { Incision } \\
\text { Excision of head of meta- } \\
\text { tarsal } \\
\text { Excision of head of first pha- } \\
\text { lanx; amputation }\end{array}$ & 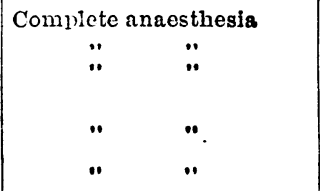 & $\begin{array}{l}\text { Internal popliteal. } \\
\text { External popliteal. } \\
\text { Internal saphenous. } \\
\text { External saphenous. } \\
\text { Posterior tibial. }\end{array}$ \\
\hline
\end{tabular}

General anaesthesia was used to complete the operation in 7 of the alove cases.

Tirree of these were ganglia at the back of the wrists in fat patients. These oscurred early in the series, and in exch case apparently a fer fibres of the musculo-spiral nerre had escaped.

In another case an cxcision of the head of the radius, the soft tissues were quite anaesthetic, but the bone remained sensitive. Here again few fibres of the musculo-spiral romained sensitive.

Two cases of adenomata of the breast had to be completed undar general anaesthesia. Although the intercostal nerves corresponding to due appurently to an unusually low distribution of the descending branches of the cervical plexus. 
the required nerve is defined, and the needle introduced through the skin a little below the level of this rib, and passed obliquely upwards until it touches the lower border. The needle is then withdrawn a fraction of an inch, the point depressed a little, and then pushed forward again. This manouvre is repeated until the point just misses the lower border of the rib. The needle is then pushed on for about a quarter of an inch well into the subcostal groove, and the injections made.

Dorsal Aspect of Foot and Ankle.

Fig. 6 illustrates the anaesthesia produced by blocking the external poplitea nerve, which can be easily reached

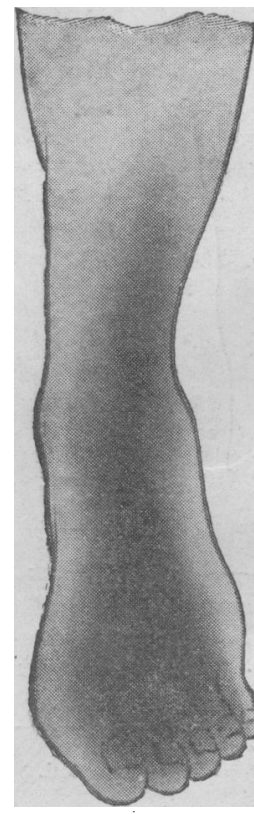

Fig. 6. as it crosses the neck of the fibula; the nerve can be felt in this position. The needle is passed down to the bone.

If following an injection of any of the foregoing nerves a complete anaesthesia corresponding to the distribution does not appear after a short interval, the needle should be reinserted, and a further quantity of the solution injected. The explanation of an incomplete anaesthesia is either that the solution is not evenly distributed around the nerve, or, in the case of the larger ones, that the analgesic fluid has not infiltrated the whole thickness of the nerve trunk, consequently some few fibres have escaped.

In the table on page 1703 is given a summary of the cases upon which this method has been used. These cases show that a very considerable variety of surgical procedures can be carried out under this form of anaesthesia.

The choice of the kind of anaesthetic to be used for any particular case must depend upon the special circumstances of that case. It is

obvious that no such thing as a routine anaesthetic or combination of an iesthetics can be employed with the best result, sinc: very varying conditions, both local and general, are present in different patients. Therefore, although it is not intended to suggest that regional anaesthesia should always be used where pos. sible, it may safely be urged that this form of anaesthesia is very valuable in those not infrequent cases in which general anaesthesi i is from some cause or another contraindicated.

The surgical treatment of severe whitlows, which forms so large a part of the work in hospital out-patients' rooms, is a very good example of the usefulness and convenience of regional anaesthesia. A long anaesthesia is required in order that the parts may be clearly defined and the exact limits of the suppuration made out.

Out-patients are frequently improperly prepared for a general anaesthetic, and a journey through the streets, even some hours after recovery from ether, cannot be regarded as desirable. The length of anaesthesia giren by novocain is far beyond anything that is likely to be required for surgery of this description, and, of course, there is the great advantage of the absence of after-effects.

The dangers of operations upon the thorax are chiefly connected with the general anaesthetics employed, and it is in the surgery of this region that regional anaesthesia is so valuable. These patients are frequently very ill indeed, suffering from embarrassed respiration and circulation, especially in such conditions as large empyemata, abscess of the lung, and pyopericardium.

Further, there is that increasing class of case in which the operation of decostalization is undertaken for the relief of chronic empyemata, bronchiectasis, etc. Here the post-operative dangers of general anaesthesia are sarious.

It is well known that one of the chief causes of pneumonia following operations is reflex rigidity of the chest and consequently inefficient expansion of lungs already to some extent damaged by a pungent vapour and more or less filled with anaesthetic sodden mucus. It is tlerafore clearly a great advantage in all cases involving a large wound of the chest wall to use a form of anaesthesia causing no pulmonary irritation.

Consequently it is in the surgery of the thorax that regional anaesthesia is most useful, and it is fortunately most easily and successfully carried out in this part of the body. Provided that the injection into the intercostal nerve is made well behind its lateral cutaneous branch, the whole thickness of the lateral wall of the thorax from the mid-line in front to within a few inches of the mid. line behind becomes anaesthetic. So that with equal facility a rib may be removed, the pericardium may be drained, or a tuberculous sternum treated.

Although the limits of this anacsthesia are really only defined by anatomy, yet it is quite obvious that there must be great objections to any form of local anaesthesia however perfect for any major operation upon the head, face, or jaws, and it is quite certain that few patients would face such an ordeal.

Finally, the uses and limitations of this method of anaesthesia may be very shortly summed up in two wordsnamely, anatomy and novocain. I should like to tako this opportunity of expressing my thanks to the surgical staff of University College Hospital for the many facilities I have been aftorded for the practice of this form of anaesthesia.

\section{CASE OF STOKES-ADAMS DISEASE.}

BY

JAMES LAW FALCONER, M.B.; Сн.B., F.R.C.S., ASSISTANT SURGEON, BOLTON INFIRMARY.

The points of interest in the following case appear to mo to be the occurrence of the disease in a woman, and the combination of all types of attack, namely, syncopal, epileptiform, and apoplectiform, in the one patient.

Mrs. A., aged 72, had enjoyed perfect health during most of her life-so much so, that she accomplished a 20 -milo walk at the age of 70 .

Seven years ago she consulted my predecessor for slight attacks of vertigo, which were put down to "liver." Off and on since then, whilst walking, she has had to stop and bend down to recover from what she called a " mazed" feeling.

In September, 1909, she was seen for attaclss of giddiness. In these she had a distinct tendency to fall, and instinctively clutched at something for support, though no actual fall took place. About this time she noticed that she was short of breath on ascending stairs, etc. She was found to have a consistently slow pulse, between 30 and 40.

I saw her for the first time on July 4th, 1910. She was simply complaining of slight malaise. The heart was normal in size, and remained so subsequently. The first sound was rather weak, but no murmur was present. The pulse-rate was 44 .

When seen on July 22nd she had had several "dizzy" attacks. Her pulse varied whilst I sat talking to her, being 34 at one time and 68 at another. Of this she was quite unconscious. She had a slight systolic murmur at the base, and her blood pressure equalled $225 \mathrm{~mm}$. Hg.

She was put on arsenic and potassium iodide, and for a few days felt much better.

On August 1st she walked some distance to a railway station, and on arriving there lost consciousness without any warning and fell heavily on the platform. She consulted me an hour later, when the only noticeable thing, apart from some natural nervousness and shock, was a slow, irregular pulse varying between 36 and 40 . Sho refused to go to bed, and next day again fell whilst talking to a groom in her stables. She was seen at midday, and whilst sitting in her chair suddenly said, "I am off!" turned pale, showed some general facial twitching, and lost consciousness for a second or two. There was a little mental confusion for a minute or so, and then she resumed conversation quite in a normal manner. A diagnosis of Stokes-Adams disease was made, and she was sent to bcd.

On August 3rd both the introduction of a nurse and the occasion of my visit signalized attacks similar to that just described, and from this time onwards she had fre. quent attacks-one or more during the day. They wero of varying severity, and in many of them she certainly did not lose consciousness. She merely exclaimed, "Ah!" 